This item was submitted to Loughborough's Research Repository by the author.

Items in Figshare are protected by copyright, with all rights reserved, unless otherwise indicated.

\title{
Evaluating the performance improvement of different pneumatic hybrid boost systems and their ability to reduce turbo-lag
}

PLEASE CITE THE PUBLISHED VERSION

http://dx.doi.org/10.4271/2015-01-1159

\section{PUBLISHER}

(C) SAE International

VERSION

AM (Accepted Manuscript)

\section{PUBLISHER STATEMENT}

This work is made available according to the conditions of the Creative Commons Attribution-NonCommercialNoDerivatives 4.0 International (CC BY-NC-ND 4.0) licence. Full details of this licence are available at: https://creativecommons.org/licenses/by-nc-nd/4.0/

\section{LICENCE}

CC BY-NC-ND 4.0

\section{REPOSITORY RECORD}

Bao, Ran, and Richard Stobart. 2015. "Evaluating the Performance Improvement of Different Pneumatic Hybrid Boost Systems and Their Ability to Reduce Turbo-lag". figshare. https://hdl.handle.net/2134/19585. 


\title{
Evaluating the Performance Improvement of Different Pneumatic Hybrid Boost Systems and Their Ability to Reduce Turbo-Lag
}

\author{
Author, co-author (Do NOT enter this information. It will be pulled from participant tab in \\ MyTechZone) \\ Affiliation (Do NOT enter this information. It will be pulled from participant tab in MyTechZone)
}

\begin{abstract}
The objective of the work reported in this paper was to identify how turbocharger response time ("turbo-lag") is best managed using pneumatic hybrid technology. Initially methods to improve response time have been analysed and compared. Then the evaluation of the performance improvement is conducted using two techniques: engine brake torque response and vehicle acceleration, using the engine simulation code, GT-SUITE [1].
\end{abstract}

Three pneumatic hybrid boost systems have been considered: Intake Boost System (I), Intake Port Boost System (IP) and Exhaust Boost System (E). The three systems respectively integrated in a sixcylinder 7.251 heavy-duty diesel engine for a city bus application have been modelled. When the engine load is increased from no load to full load at $1600 \mathrm{rpm}$, the development of brake torque has been compared and analysed. The findings show that all three systems significantly reduce the engine response time, with System I giving the fastest engine response.

The vehicle performance has been also considered. Systems I and IP have been integrated respectively into the bus model giving two different configurations. The acceleration capability of the two types of vehicle has been simulated. Both Systems I and IP significantly reduce the vehicle acceleration time by substantially reducing turbolag.

\section{Introduction}

Pneumatic hybrid technology refers to the use of storage of compressed air as a means of energy recovery in a vehicle system. A pneumatic hybrid system stores compressed air during the braking process. The compressed air can be re-used either to realize a regenerative Stop-Start function or to improve the engine performance by injecting compressed air into the inlet manifold to build-up engine torque more rapidly compared with the unassisted engine [2].

As described in [2], the pneumatic hybrid technology has benefits that accrue from using the stored compressed air to reduce turbo-lag. Turbo-lag is observed when engine load is increased. Increasing air flow to the cylinders is the result of a series of energy transfers in the air system which requires time to stabilize. Consequently the air-fuel ratio falls since the air-supply cannot immediately match the increased fuelling that corresponds to the load demand on the engine.
To limit particulate emissions, the quantity of fuel injected is controlled by a smoke limiting function implemented in the engine management system and is adjusted to match the supply of fresh air.[3] As a result, the engine spends longer at part load conditions so that both fuel consumption and exhaust emissions may be adversely affected. The response time of the air system may be reduced either by directly increasing the air-supply to the cylinders or by directly accelerating the turbocharger using an external torque source such as an electric motor.[4] The direct supply of air, made possible in the pneumatic hybrid system, can rapidly help develop the cylinder torque corresponding to a normal level of boost.

For vehicle applications of the diesel engine, there are three aspects to managing turbocharger response time [4]:

1. Controlling of the fuel flow;

2. Speeding up of the system (engine, manifolds and turbocharger) response;

3. Increasing of the number of transmission gears for vehicular applications.

The first method, control of the fuel flow, has been analysed in detail [4], as one way to manage turbo-lag. It is recognized as a 'passive' method because the low air supply and low injected fuel mass cause a slower engine response and poor vehicle drivability. The third method, to increase of the number of transmission gears, has also been considered as a 'passive' method for the reason that more gear ratios to make use of the available torque worsen drivability owing to the much more frequent gear-changes required. Both first and third methods are intended to cure the symptom of black smoke emission rather than the underlying cause of the turbocharger delay.[4] The second method, speed-up of the system (engine, manifolds and turbochargers) response, is considered an 'active' method in [4], because it improves the transient response of the engine, manifolds and turbocharger. The focus of this paper is on the realization of the second method by use of stored compressed air during braking events.

We consider first an analysis of three system concepts:

- $\quad$ Intake Boost System (System I),

- Intake Port Boost System (System IP) and

- $\quad$ Exhaust Boost System (System E), 
respectively integrated in a six-cylinder 7.251 heavy-duty diesel engine. The three concepts have been respectively modelled in a 1-D engine code, and the performance changes, analysed in detail. When the engine accelerates from no load to full load at $1600 \mathrm{rpm}$, the development of brake torque has been compared and analysed. Then the performances of respectively two different pneumatic hybrid city bus configurations (System I and IP), have been considered. The acceleration capability of the two types of vehicle has been simulated and the results compared.

\section{Investigation of Response Time Improvement}

In general, when an additional load is applied to an engine, the current torque output of the engine cannot instantly match the increased load requirement and as a result, the engine speed drops. Note that a sophisticated feed-forward control could seek to match fuelling and a predicted load, but there is always likely to be some mismatch. A speed change is monitored by the engine controller which will increase the fuel injection mass to increase engine speed. However, the turbocharger cannot instantly supply the corresponding required air flow requirement to the cylinders which tends to cause a reduction in the air-fuel ratio. Therefore, the higher fuel mass and lower air supply tends to causes inefficient combustion and insufficient exhaust gas energy to speed-up the turbocharger. The two most prominent examples are respectively the vehicle climbing a hill or engaging the clutch after a gear change.

The speed transient event normally happens when the driver requires a significant acceleration. After the driver fully depresses the accelerator pedal, the engine controller sends out the maximum fuel mass injection signal. Since the resistance torque remains unchanged and the compressor air-supply cannot yet match the higher injected fuel mass, the air-fuel ratio decreases as the air supply slowly increases. The low air-fuel ratio in both load and speed increase transient events leads to poor combustion and consequently increased particulate emissions and poor fuel economy.

\section{Approaches to improving turbocharger response time - Analysis}

In a turbocharged engine there is no mechanical connection between turbocharger and the engine crankshaft. Therefore, turbocharger and engine speeds are coupled through the gas dynamics of inlet and exhaust. The boost pressure and mass flow rate of the compressor is related compressor map such as the one shown in Figure 1. The map is developed at steady state conditions and can be considered as a reasonable approximation for transient conditions where changes propagate at the local speed of sound. However for significant transient changes, this information is supplemented by both turbine maps and the dynamic behaviour of the turbocharger.

From the compressor map, it can be seen that it is unrealistic for the turbocharger to achieve both high boost pressure and air-mass flow rate at its low working speed. An acceleration process is required to take the device from its low boost pressure and air-mass flow rate operation point to its high load condition. To achieve the new operating point, the turbine power must exceed the compressor power to speed-up the turbocharger. The following differential equation describes the angular rotation of the turbocharger shaft as a result of applied torques. All the mechanical losses are encapsulated in the mechanical efficiency.

Page 2 of 14

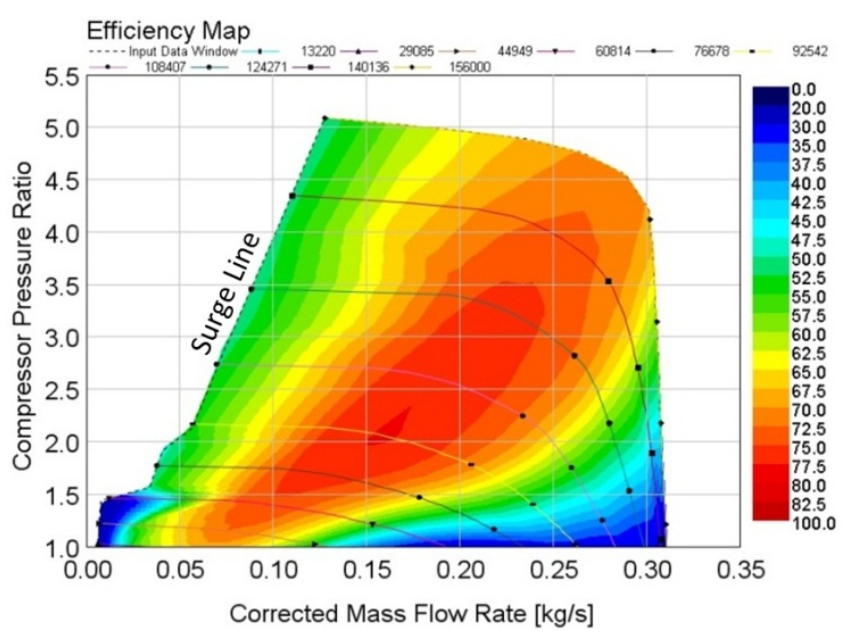

Figure 1. Typical map of aerodynamic type turbocharger compressor

$$
\eta_{m T C} \tau_{T}-\left|\tau_{C}\right|=G_{T C} \frac{d \omega_{T C}}{d t}
$$

$\tau_{\mathrm{C}}(\mathrm{N} \cdot \mathrm{m}) \quad$ - the instantaneous value for the compressor torque, $\tau_{\mathrm{T}}(\mathrm{N} \cdot \mathrm{m}) \quad$ - the instantaneous value for the turbine torque, $\eta_{\mathrm{mTC}}(-) \quad$ - the turbocharger mechanical efficiency, $\mathrm{G}_{\mathrm{TC}}\left(\mathrm{kg} \cdot \mathrm{m}^{2}\right)$ - the turbocharger rotating inertia, $\omega_{\mathrm{TC}}\left(\mathrm{rad} / \mathrm{s}^{2}\right)-$ the turbocharger angular velocity.

From the equation (1), it can be seen that to improve the transient response during a demand for greater air flow, the approaches can be:

Approach 1: Increase the turbine torque, means increasing or supplementing the $\tau_{\mathrm{T}}$.

Approach 2: Reduce the moment of inertia of turbocharger, means reducing the $\mathrm{G}_{\mathrm{TC}}$.

Approach 3: Reduce the turbocharger shaft mechanical losses, means increasing the $\eta_{\mathrm{mTC}}$.

The overall target for these methods is increase the turbocharger angular acceleration, $\frac{d \omega_{T C}}{d t}$. Approach 2 and Approach 3 both relate to the turbocharger configuration and have been analysed in detail in [4], and will not be covered in detail in this paper. Also Approach 3 seems like an effective means to improve the turbocharger transient response from theoretical analysis, but it can only offer small scope for improvement. Some suggestions based on Approach 2 and Approach 3 are given in [4] and summarized as follows:

1. Adopting lighter materials to reduce the turbocharger moment of inertia appears straightforward since the machine aerodynamics is unchanged although manufacturing costs may be increased.

2. Use of more than one small turbocharger instead of a single (larger) unit reduces inertias but represents a major increase in the system complexity.

3. Reduction of turbine (and compressor) rotor diameters respectively will strongly influence turbocharger and, consequently, engine speed response.

Approach 1, increasing the turbine torque, is the key topic of this research and will be discussed in detail. In order to increase the turbocharger transient response, two possible solutions are: 
Solution 1: Supplement the turbine torque using an additional torque input device on the turbocharger shaft.

Solution 2: Increase the amount of the available energy in the exhaust gas.

Approach 1 will be analysed in detail in the following sections. Figure 2 shows a classification of various methods of reducing turbolag. In this paper, the methods in the orange background are detailed investigated, and the method in blue background will be briefly introduced as a reference here.

Electric assistance for turbocharging is gaining in popularity, but is included here for comparison purposes. We present no further analysis but recognise that a detailed comparison on the basis of fuel economy and cost effectiveness is warranted and may form an aspect of our continuing work.

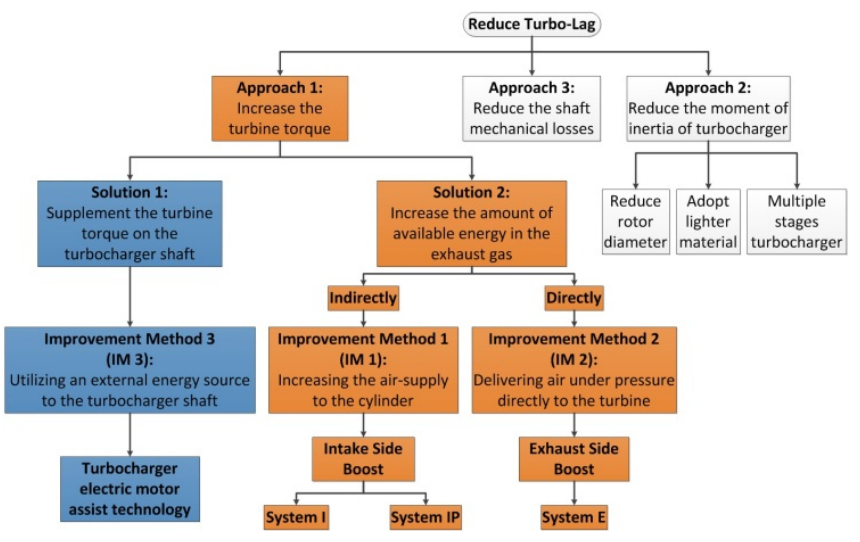

Figure 2. Classification of various method of reducing turbo-lag

\section{Methods of Improving the Turbocharger Transient Response by Increasing the Turbine Torque}

The methods to improve the turbocharger transient response by increasing the turbine torque can be implemented at the intake, exhaust or the turbocharger shaft itself.

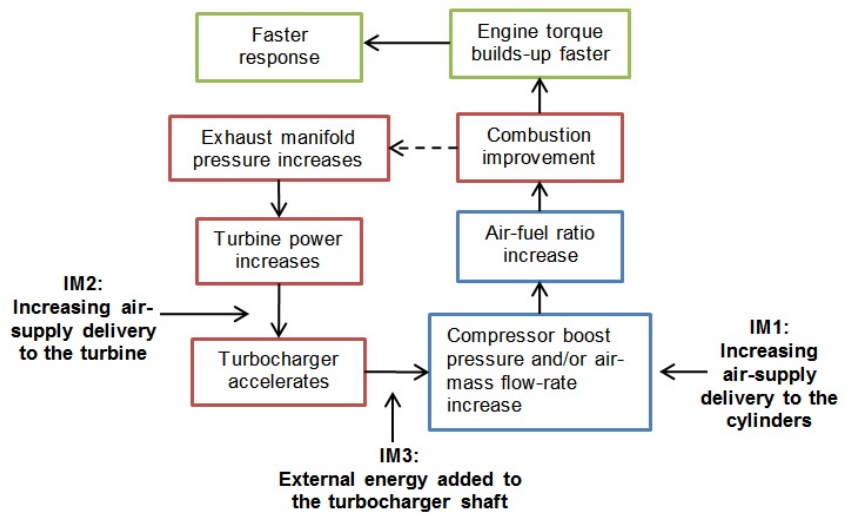

Figure 3. Main mechanism of improving turbocharger transient response

Improvement Method 1 (IM1): On the inlet side, directly increasing the air-supply delivery to the cylinders.
Improvement Method 2 (IM2): On the exhaust side, delivering air under pressure directly to the turbine.

Improvement Method 3 (IM3): For the turbocharger shaft, utilizing an external energy source is recognized as a practical choice.

The role of these methods in improving the turbocharger transient response is shown in Figure 3.

\section{Improvement Method 1 (IM1)}

IM1 increases air delivery to the cylinders and can be realized by injecting pressurized air stored in the air tank(s) into the intake manifold or directly into the cylinders. The injected air is instantly available to the engine for combustion. Therefore, the duration of combustion discrepancies is reduced since the direct increase of airsupply will also matches the increased fuel quantity to meet the load requirements. As a result, the full combustion process gives both high combustion torque and the normal exhaust enthalpies required to bring the turbocharger up to speed.

Nowadays, increased engine ratings generally result in higher inlet manifold volumes, hence slower response in the intake side.[4] Because the compressed air must both increase in the manifold pressure as well as increase air delivery to the cylinders, the position at which air is injected into the intake manifold is an important factor in the response improvement. The nature of the improvement brought about by IM1 is apparent in Figure 3. IM 1 is closest of all the proposed changes to the combustion process. As a result, IM1 should have the fastest air-supply increase and consequently the greatest effect on response time.

One example of the implementation of this method is the Pneumatic Boost System (PBS) reported by Marx et al. in [3]. The PBS has been developed by the Knorr-Bremse Company to realize a significant improvement in the response and acceleration behaviour of the engine and the vehicle. [3] The engine, an 81 diesel engine with exhaust gas recirculation and two-stage turbocharging, without PBS achieve $90 \%$ of its maximum torque in almost $5 \mathrm{~s}$, whereas the same engine with PBS achieves this value in $0.7 \mathrm{~s}$.

\section{Improvement Method 2 (IM2)}

IM2 which increases the air-supply delivery to the turbine, can also be realized by implementing the pneumatic hybrid technology to inject the compressed air into the exhaust manifold as an additional flow of energy to the turbine. Air injection into the exhaust manifold is less efficient than air injection into the intake manifold, since there is still a lag between the intake and exhaust side. There is also the loss of availability resulting from injection of relatively cool air into the exhaust manifold during the acceleration process. Although the exhaust manifold pressure is increasing following the boost in fuelling, the inertia of the turbocharger as well as the gas dynamics of filling the intake manifold cause a further lag on the intake side. From Figure 3, it can be seen that the IM2 is the most remote from combustion with changes having to propagate through turbine, compressor and intake manifold.

An implementation of this method, BRaking Exhaust Energy Storage (BREES) is demonstrated in [5]. The experiments were conducted by using a 2.01 light-duty diesel engine equipped with Exhaust Gas Recirculation (EGR) and Variable Geometry Turbine (VGT) to evaluate the engine transient response during in-gear braking and 
acceleration. The result showed that the BREES system had a much sharper brake torque increase compared with the conventional configuration. Additional, the experimental results confirm that the proposed system reduces the time to reach the torque requirement during the 3rd gear tip-in by about $60 \%$.

\section{Improvement Method 3 (IM3)}

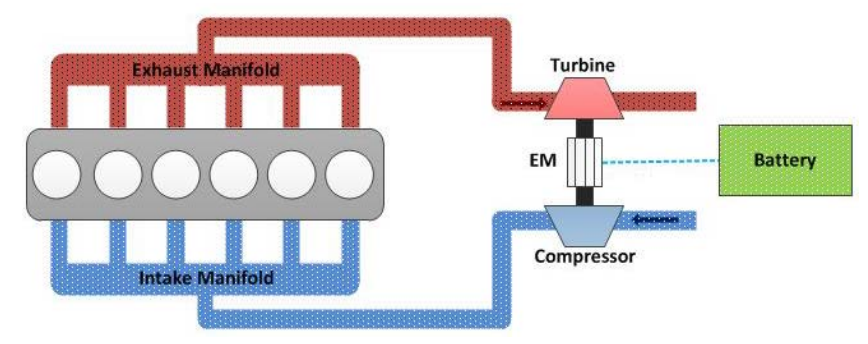

Figure 4. Schematic diagram of diesel engine with turbocharger electric motor assist

With IM3, external energy added to the turbocharger shaft, can be realized by using different kind of energy source such as electrical or hydraulic assistance.

One possible solution is Electric Assist Technology (EAT) using an electric motor mounted on the turbocharger shaft. The motor offers additional torque to the turbocharger when a load or speed increase is required. A schematic diagram is shown in Figure 4.

The Equation (1) described the relationship between the normal, unassisted turbocharger shaft torque and the turbocharger angular acceleration. For the turbocharger with the electric motor assist, the respective balance is given by Equation (2).

$$
\eta_{m T C} \tau_{T}+\tau_{E M}-\left|\tau_{C}\right|=G_{T C+E M} \frac{d \omega_{T C}}{d t}
$$

$\tau_{\mathrm{C}}(\mathrm{N} \cdot \mathrm{m}) \quad-$ the instantaneous value for the compressor torque, $\tau_{\top}(\mathrm{N} \cdot \mathrm{m}) \quad$ - the instantaneous value for the turbine torque,

$\tau_{\mathrm{EM}}(\mathrm{N} \cdot \mathrm{m}) \quad-$ the electric motor torque,

$\eta_{\mathrm{mTC}}(-) \quad-$ the turbocharger mechanical efficiency,

$\mathrm{G}_{\mathrm{TC}+\mathrm{EM}}\left(\mathrm{kg} \cdot \mathrm{m}^{2}\right)$ - the combined turbocharger and EM mass moment inertia,

$\omega_{\mathrm{TC}}\left(\mathrm{rad} / \mathrm{s}^{2}\right) \quad$ - the turbocharger angular velocity.

For a successful integration of the electric motor, the established turbocharger shaft acceleration must fulfil the following relation.

$$
\frac{\eta_{m T C} \tau_{T}+\tau_{E M}-\left|\tau_{C}\right|}{G_{T C+E M}}>\frac{\eta_{m T C} \tau_{T}-\left|\tau_{C}\right|}{G_{T C}}
$$

From equation (3), the electric motor torque can be represented from equation (4).

$$
\tau_{E M}>\frac{\Delta G}{G_{T C}}\left(\eta_{m T C} \tau_{T}-\left|\tau_{C}\right|\right)
$$

$\tau_{\mathrm{C}}(\mathrm{N} \cdot \mathrm{m}) \quad-$ the instantaneous value for the compressor torque, $\tau_{\mathrm{T}}(\mathrm{N} \cdot \mathrm{m}) \quad$ - the instantaneous value for the turbine torque,

$\tau_{\mathrm{EM}}(\mathrm{N} \cdot \mathrm{m})$ - the electric motor torque,

$\eta_{\mathrm{mTC}}(-) \quad-$ the turbocharger mechanical efficiency,

$\mathrm{G}_{\mathrm{TC}}\left(\mathrm{kg} \cdot \mathrm{m}^{2}\right)$ - the turbocharger rotating inertia,

$\Delta G\left(\mathrm{rad} / \mathrm{s}^{2}\right)$ - the increment of the rotating inertia.

Page 4 of 14
Equation (4) indicated that when electric motor added to the turbocharger, the balance of the motor torque and increment of shaft inertia when the electric motor installed should be careful considered.

There are two benefits to adopting the electric motor assist to the turbocharger. Respectively, firstly the ability of the engine to operate at overall higher boost pressure levels.[4] Secondly the electric motor not only can function also a generator. At low engine speed, when there is a load or speed increase transient event, electric power is supplied to the turbocharger shaft aiding its fast acceleration. At high engine speed, instead of wasting the energy that exceeds the compressor requirement, the electric motor can convert to the electricity generator to recover the energy and store in energy storage such as a battery or a super-capacitor. But the EAT has same disadvantages that prevent widespread application at low cost. First is a more complex control system which includes the control strategy of the electric motor. Second is the durability and reliability of the turbocharger remains to be proven.

\section{Using Pneumatic Hybrid Boost System to Improve the Turbocharger Transient Response}

\section{Pneumatic Hybrid Boost Technology}

As mentioned before, increasing the air supply to the cylinders or to the turbine both can be considered as effective methods to improve the engine transient response. The pneumatic hybrid boost system has inherent advantages to implement these methods above to improve the transient response because of the ready availability of an air supply. The air stored in the air $\operatorname{tank(s)}$ can be reused to improve turbocharger response time by injecting air into the intake or exhaust manifold. To realize the boost function, there are two different engine structures can be considered as candidates.

The first proposed structure, intake side boost (ISB), is a realisation of IM1. In order to increase the air-supply to the cylinders for combustion, the air can be injected into the intake at different points such as the intake manifold or the intake ports. An example of ISB is shown in Figure 5, in which the compressed air stored in the air tank is supplied to the cylinders through the intake manifold at the time when acceleration of the turbocharger is required. When the load or speed demand is made, the compressed air is injected into the intake manifold in order to match the increased fuel injection mass. The precise air flow is controlled by the Air Tank Valve (ATV). The Intake Manifold Valve (IMV) will fully close during the injection period to prevent the compressed air being injected back to the compressor. Because the air can be immediately used to support combustion in the cylinders, the resulting high exhaust gas energy causes a faster turbocharger and engine response to reduce turbo-lag. In order to avoid the compressor enter an unstable operation condition, two methods can be implemented. First is when the pressure of the volume between the IMV and compressor reaches a threshold value, the IMV will open to avoid the stall condition of the compressor. Second method is to set a bypass or wastegate after the compressor which can keep the compressor output pressure constant. 


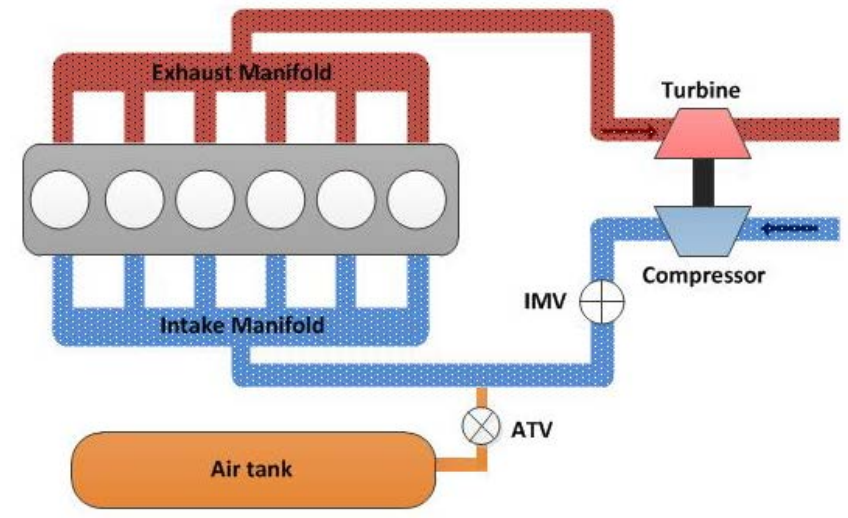

Figure 5. Schematic diagram of the ISB engine structure

The second proposed structure, exhaust side boost (ESB), realises IM2. An example of ESB called System E is shown in Figure 8, in which compressed air in the air tank is supplied to the exhaust system to speed up the turbine directly. As a result, the compressor will accelerate to increase the flow of air into the inlet manifold and build up the intake manifold pressure. When the turbocharger reaches its normal operating point (in relation to engine speed and load), the injection of compressed air will cease.

\section{Intake Side Boost}

There are several ways to implement ISB in the pneumatic hybrid engine. Each requires some new devices be added into the engine. Two different structures will be considered:

1. Intake Boost System (System I).

2. Intake Port Boost System (System IP).

\section{Intake Boost System (System I)}

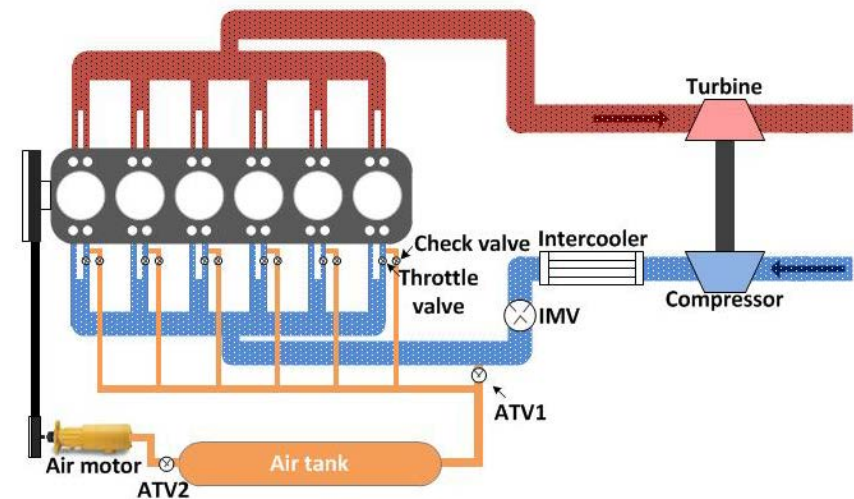

Figure 6. System diagram for System I

Figure 6 shows the arrangement of equipment with some new devices added to the original pneumatic hybrid engine structure that was first shown in [2]. The original pneumatic hybrid engine devices like the air tank, Compression Release Engine Braking Device (CREBD), air tank, air motor, Check Valve (CV) and Throttle Valve (TV) are retained. The new devices are respectively the connection pipes between the air tank and the intake manifold with the Air Tank Valve 1 (ATV1), and the Intake Manifold Valve (IMV) in the intake manifold downstream of the intercooler. The function of IMV is to

Page 5 of 14 prevent the compressed air being injected back to the compressor. Such an increasing pressure has the tendency to move the compressor operating point towards surge.

In normal operation, when the engine does not require high air demand and the compressor can supply enough pressure, both IMV and TVs fully opens to let the engine operate in the normal turbocharged mode.

When the compressor cannot supply enough air to the engine in a highly dynamic situation like acceleration or on steep gradients, System I is activated. The high pressure air from the air tank injects into the manifold through the ATV1. The IMV closes and TVs fully open. The injection of air ends when the compressor delivery pressure is higher than the pressure of the injected air. At this point IMV opens and ATV1 closes.

\section{Intake Port Boost System (System IP)}

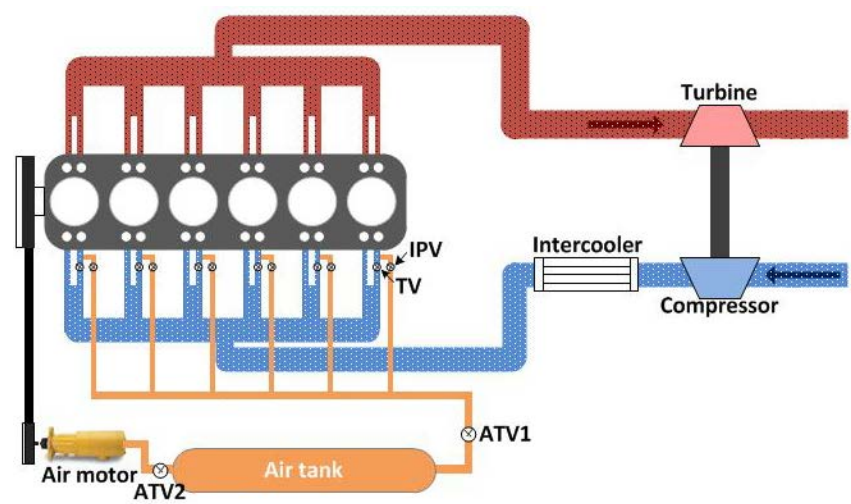

Figure 7. System diagram for System IP

Compared with System I, System IP injects the compressed air directly into the cylinders by connecting the air tank and the intake port with pipes and six Intake Port Valves (IPVs) as shown in the Figure 7. Also six Throttle Valves (TVs) are installed at each intake port to prevent compressed air being injected back into the compressor. A high pressure common air rail connects ATV1 and IPVs on each intake port.

In the normal operation, when the engine does not require high air demand and the compressor can supply enough pressure, the TVs fully open while the IPVs and ATV1 fully close.

During an engine transient when the compressor is unable to supply enough air to the engine, System IP is activated. The high pressure air from the air tank is injected into the high pressure air rail through ATV1, and in turn the air is injected into the cylinder by means of the IPVs. The TVs on each intake port fully close during the injection. The injection will end when the pressure that the compressor builds is higher than the pressure of the injected air. The TVs fully open again and the IPVs close.

According to where the compressed air is injected into the intake manifold the dynamics of the air supply change. Pressurising the whole manifold compared with supplying air to the inlet ports will be a slower, but more complex in the mechanical design. Compared with System I, System IP can deliver the compressed air more quickly since it only need fill a small volume auxiliary chamber between the TV, IPV and intake valve in each intake port. Moreover, 
System IP allows the compressor to accelerate to its normal operating condition without risking surge or stall. Only one intake port is blocked by the TV during the compressed air injection. The compressor will continue deliver the air into the intake manifold at its operation point approach the normal value.

\section{Exhaust Side Boost}

Injecting compressed air into the intake manifold has received considerable attention, but the performance improvement offered by this concept is severely constrained by the compressor surge limit.[5] Injecting the compressed air into the exhaust manifold avoids compressor surge and is another method to reduce turbo-lag by using the pneumatic hybrid technology.

\section{Exhaust Boost System (System E)}

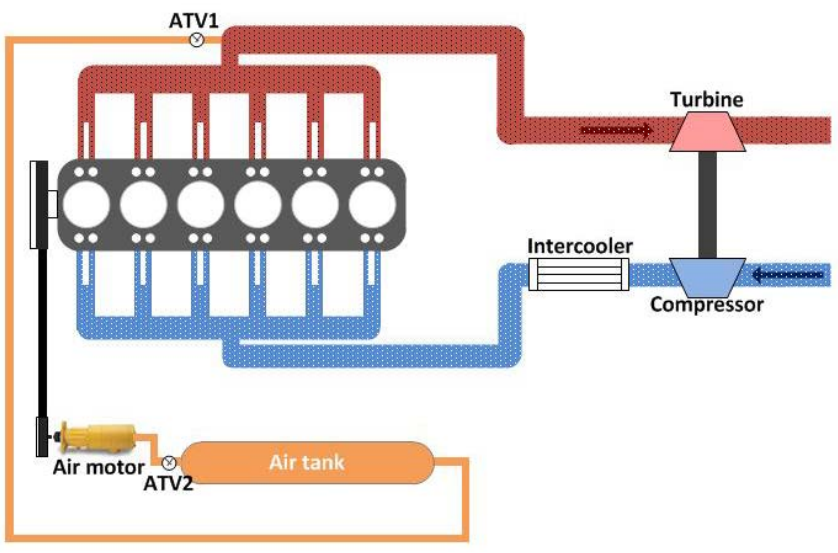

Figure 8. System diagram for System E

System E has a similar structure with System I. Figure 8 shows system diagram for System E. Unlike System I, the air tank connects the exhaust manifold with the Air Tank Valve 1 (ATV1).

In normal operation, when the engine does not require high air demand and the compressor can supply enough pressure, System E will not be activated, the TVs are fully open and the CVs fully closed to with the engine operating in normal mode.

When System E is working, the high pressure air from the air tank is injected into the exhaust manifold through ATV1 to accelerate the turbocharger to its target speed. Air injection ends when the intake manifold pressure reaches its normal working pressure according to engine speed and load.

From this qualitative analysis we can observe that IM2 is least effective of the methods under review because of the long process path apparent from the process diagram for boost, Figure 3. It has the substantial advantage that the compressor operating point is reached without risk of surge or stall.

\section{Engine with Pneumatic Hybrid Boost System Simulation Models and Results Comparison}

\section{Basic Engine Simulation Model}

To simulate the transient response improvement made by three different pneumatic hybrid boost systems, respectively System I, IP and $\mathrm{E}$, a 1-D engine simulation code, GT-POWER, was used to simulate the engine performance when a load transient is applied to the engine.

Table 1. Main technical parameters of YC6A series engines: the target engine data is shown in bold [6]

\begin{tabular}{|c|c|c|c|c|c|c|}
\hline Model & $\begin{array}{l}\text { YC6A } \\
240-30\end{array}$ & $\begin{array}{l}\text { YC6A } \\
260-30\end{array}$ & $\begin{array}{l}\text { YC6A } \\
280-30\end{array}$ & $\begin{array}{l}\text { YC6A } \\
220-31\end{array}$ & $\begin{array}{l}\text { YC6A } \\
240-31\end{array}$ & $\begin{array}{l}\text { YC6A } \\
260-31\end{array}$ \\
\hline Type & \multicolumn{6}{|c|}{$\begin{array}{l}\text { Vertical, in-line, water-cooled, } 4 \text { stroke, electronic control, } \\
\text { direct injection }\end{array}$} \\
\hline $\begin{array}{l}\text { Electronic } \\
\text { control system }\end{array}$ & \multicolumn{3}{|c|}{$\begin{array}{l}\text { High pressure \& common } \\
\text { rail }\end{array}$} & \multicolumn{3}{|c|}{ Electronic Unit Pump (EUP) } \\
\hline No. of Cylinders & \multicolumn{6}{|l|}{6} \\
\hline $\begin{array}{l}\text { Bore*Stroke } \\
(\mathrm{mm} * \mathrm{~mm})\end{array}$ & \multicolumn{6}{|c|}{$108 * 132$} \\
\hline $\begin{array}{l}\text { Displacement } \\
\text { (L) }\end{array}$ & \multicolumn{6}{|l|}{7.25} \\
\hline Intake way & \multicolumn{6}{|c|}{ Turbo-charging \& inter-cooling } \\
\hline $\begin{array}{l}\text { Rated } \\
\text { power/speed } \\
(\mathrm{kW} / \mathrm{r} / \mathrm{min})\end{array}$ & $\begin{array}{l}177 / \\
2300\end{array}$ & $\begin{array}{l}191 / \\
2300\end{array}$ & $\begin{array}{l}206 / \\
2300\end{array}$ & $\begin{array}{l}162 / \\
2300\end{array}$ & $\begin{array}{l}177 / \\
2300\end{array}$ & $\begin{array}{l}191 / \\
2300\end{array}$ \\
\hline $\begin{array}{l}\text { Max. } \\
\text { torque/speed } \\
(\mathrm{N} \cdot \mathrm{m} / \mathrm{r} / \mathrm{min})\end{array}$ & $\begin{array}{l}900 / \\
1400 \sim \\
1600\end{array}$ & $\begin{array}{l}1000 / \\
1400 \sim \\
1600\end{array}$ & $\begin{array}{l}1100 / \\
1400 \sim \\
1600\end{array}$ & $\begin{array}{l}850 / \\
1400 \sim \\
1600\end{array}$ & $\begin{array}{l}900 / \\
1400 \sim \\
1600\end{array}$ & $\begin{array}{l}1000 / \\
1400 \sim \\
1600\end{array}$ \\
\hline Application & \multicolumn{6}{|c|}{ 11-13.7m City Bus, 9-11m Coach } \\
\hline
\end{tabular}

A heavy-duty, 6 cylinders, turbocharged \& intercooled diesel engine based on the YUCHAI YC6A Series engine is modelled in GTPOWER as shown below in Figure 9. The YC6A series diesel engine is a new type turbocharged \& intercooled diesel engine co-developed by YUCHAI Group in China, and FEV Company in Germany.[6] The reason for adopting the four valve design is to achieve competitive torque and fuel economy at low engine speed which is a particular requirement of the city bus application. The main technical parameters of YC6A series engines are shown in Table 1.

Here, the YC6A240-30 is chosen as the base engine for the study. Its GT-POWER engine model which includes a 'DIWiebe' combustion sub model and a 'WoschniGT' heat transfer sub model is shown in Figure 9. The 'DIWiebe' model imposes the combustion burn rate for direct-injection, compression-ignition engines using a three-term Wiebe function, and is used to define the injection system, cylinder geometry, valve lift and valve timing.[7] 'WoschniGT' indicates that the in-cylinder heat transfer will be calculated by a formula which closely emulates the classical Woschni correlation without swirl.[8] The heat transfer model is used to define heat transfer characteristics of the flow component in the engine model. 


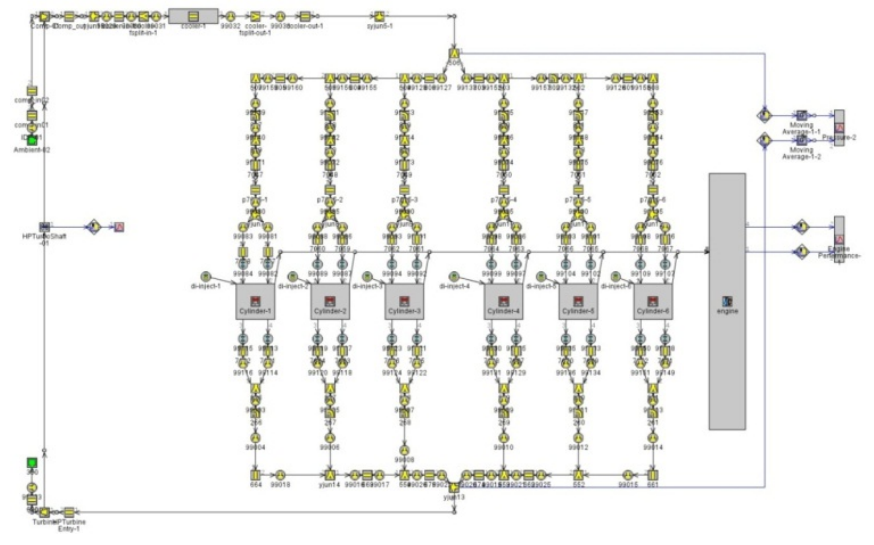

Figure 9 GT-POWER model of the basic engine

\section{Simulation of the Engine with System I}

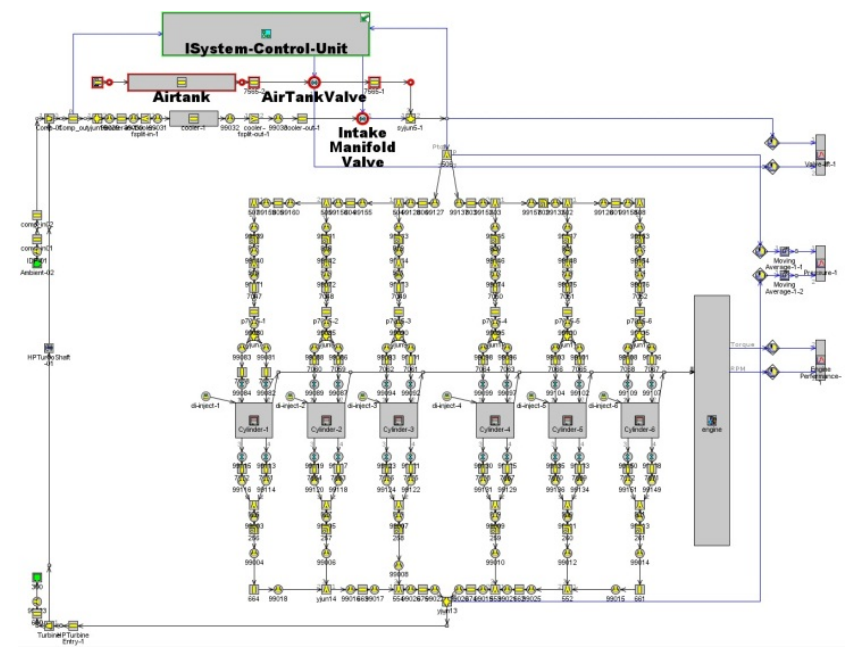

Figure 10. GT-POWER model of the engine with System I

Figure 10 shows the GT-POWER model of the engine with System I. Compared with the basic engine model, some new modules, ISystemControl-Unit (highlighted in green), and pneumatic hybrid system (highlighted in red) are added into the model. The pneumatic hybrid system includes one air tank, pipes, one air tank valve and an intake manifold valve. The check valves and throttle valves at each intake port as shown in the Figure 6 are removed here because (see [2]), the function of these valves is to recover the air when the engine is working in compressor mode during braking. In this simulation model, only the ability of System I to improve engine performance aspect is investigated. Other components, not included in the simulation of this function are excluded from the model.

The purpose of this simulation model is to investigate first the feasibility and then the performance capability of System I. Also the simulation result will be compared with other kinds of pneumatic hybrid boost system. The dimensions and characteristics for System I are shown in the Table 2. The size of the air tank follows the recommendation of the air starter manufacturer manual [9] to store sufficient compressed air for the usage of the air starter. To save the space when the pneumatic hybrid system installed on the vehicle in the future, the minimum recommendation air tank volume, $151 \mathrm{l}$, is chosen here. The dimensions of other parts are based on the previous research conducted by Lee. [10]

For simulation purpose the valves are idealised. Flow losses and valve dynamics are neglected. We believe the effects to be of second order and not influential on the initial conclusions. However a detailed investigation will need to consider valve behaviour in order to evaluate the detailed effect on systems response and the fuel economy gains. Valve operating procedures will also change air flow in manifolds and the engine cylinders, changing the patterns of losses. Again we believe such effects are second order, but require investigation in the next phase of our work.

Table 2. Dimensions and characteristics for System I

\begin{tabular}{|c|c|c|c|}
\hline Part Name & Type & $\begin{array}{l}\text { Dimensions or } \\
\text { characteristics }\end{array}$ & \\
\hline \multirow[b]{2}{*}{ Airtank } & \multirow[b]{2}{*}{ Round Pipe } & Volume (l) & 151 \\
\hline & & $\begin{array}{l}\text { Initial pressure } \\
\text { (bar) }\end{array}$ & 5 \\
\hline \multirow{2}{*}{$7565-1$} & \multirow{2}{*}{ Round Pipe } & Diameter (mm) & 25.4 \\
\hline & & Length (mm) & 30 \\
\hline AirTankValve & $\begin{array}{l}\text { Valve that the lift is imposed } \\
\text { by an Actuator Part }\end{array}$ & Diameter (mm) & 25.4 \\
\hline \multirow{2}{*}{$7565-2$} & \multirow{2}{*}{ Round Pipe } & Diameter (mm) & 25.4 \\
\hline & & Length (mm) & 1000 \\
\hline IntakeManifoldValve & $\begin{array}{l}\text { Valve that the lift is imposed } \\
\text { by an Actuator Part }\end{array}$ & Diameter (mm) & 80 \\
\hline
\end{tabular}
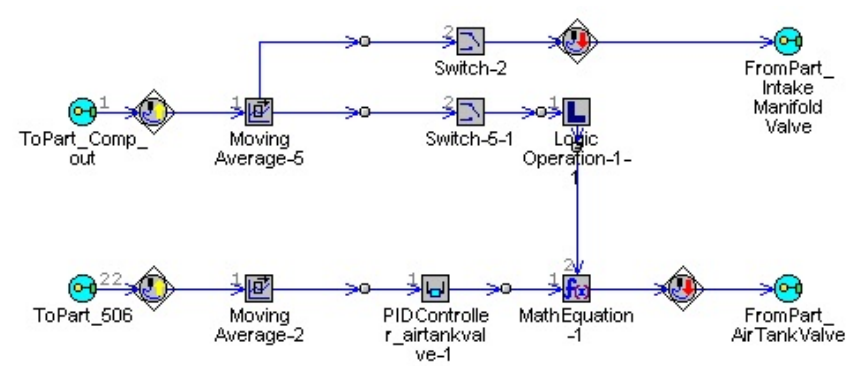

Figure 11. System diagram of ISystem-Control-Unit

Figure 11 is the system diagram of the ISystem-Control-Unit. The function of the ISystem-Control-Unit is to control the two valves based on the pressure from two pressure sensors:

- Compressor outlet pressure $\mathrm{p}_{2}$ (comes through ToPart_Comp_out)

- $\quad$ Pressure downstream of the Intake Manifold Valve (comes through ToPart_506) - which in turn becomes the target pressure for a control loop controlling ATV lift

Based on the results of comparing the pressures of two positions mentioned before, the ISystem-Control-Unit will control the two valves. The flow chart of System I control strategy is also shown in Figure 12. 
1. If the air tank pressure is sufficient to boost the engine, which means the air tank pressure $\mathrm{p}_{\mathrm{AT}}$ is greater than the limit pressure $\mathrm{p}_{\mathrm{L}}$, and the compressor is unable to supply the target boost pressure $\mathrm{p}_{\mathrm{T}}$ $\left(\mathrm{p}_{2}<\mathrm{p}_{\mathrm{T}}\right)$, System I will be activated. The control unit will open the Air Tank Valve to inject compressed air into the manifold, while the Intake Manifold Valve will be closed. When $\mathrm{p}_{2}$ is greater than the IMV opening threshold pressure $\mathrm{p}_{t}$, the IMV will open to prevent the compressed air causing compressor a surge. The system will be turned off and the ATV will be closed until the intake manifold pressure reaches the target boost pressure.

2. If the air tank pressure is not sufficient, which means the air tank pressure $\mathrm{p}_{\mathrm{AT}}$ is less than the limit pressure $\mathrm{p}_{\mathrm{L}}$, to boost the engine the control unit will not activate System I. As a result, the Air Tank Valve will be closed and the Intake Manifold Valve will be opened to supply air to the cylinders.

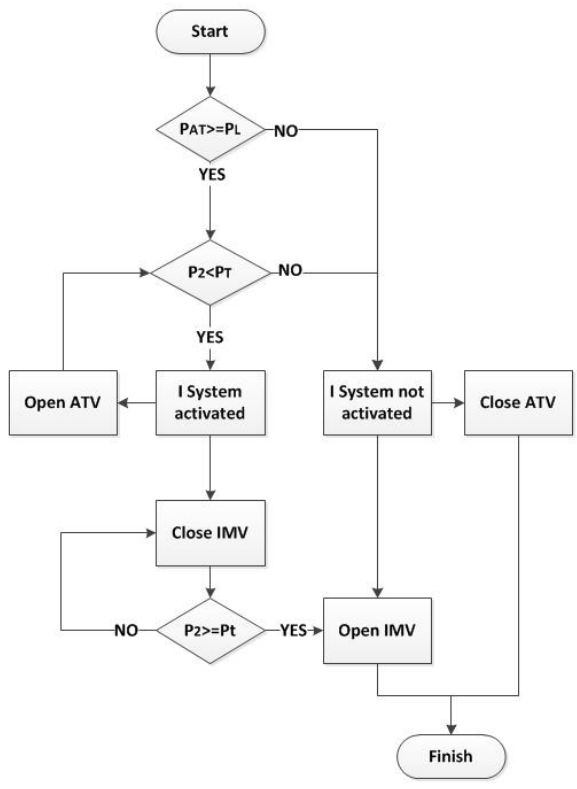

Figure 12. Flow chart of the System I control strategy

\section{Simulation of the Engine with System IP}

As shown in the Figure 13, some new modules, IPSystem-ControlUnit (highlighted in green), and pneumatic hybrid system (highlighted in red) are added to the basic engine model. The system includes one air tank, pipework, a single Air Tank Valve, six Intake Port Valves and six Throttle Valves. The ATV and six IPVs are connected to using a high pressure air rail.

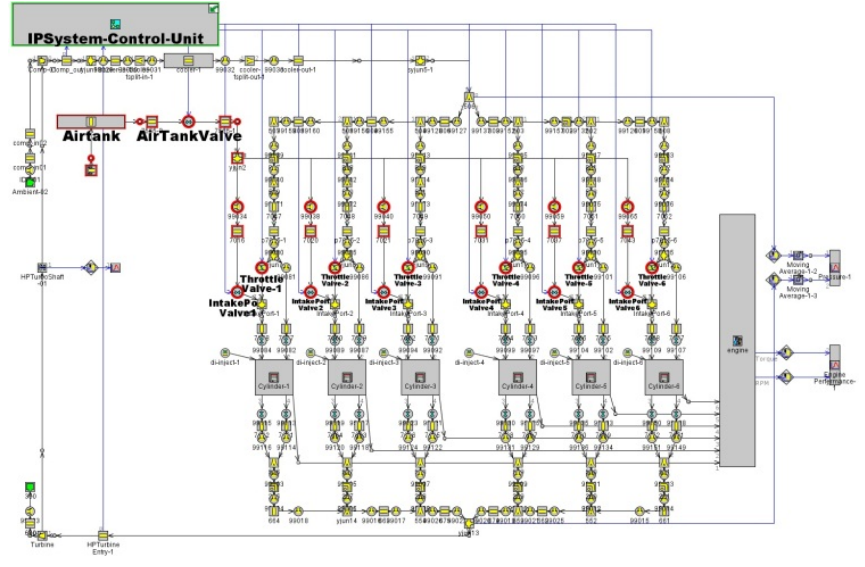

Figure 13. GT-POWER model of the engine with System IP

When System IP is activated, the high pressure air from the air tank is injected into the high pressure air rail through the ATV. In turn the air will be injected into the cylinder by means of the IPVs. The function of the TVs on each intake port is to prevent the compressed air leaking back into the inlet manifold. The injection will end when the pressure that the compressor builds is higher than the pressure of the injected air. The TVs will fully open again and the IPVs will close.

The dimensions and characteristics for System IP are shown in the Table 3. The air tank is kept at the same volume for consistency. Other design parameters are those developed by Lee [8].

Table 3. Dimensions and characteristics for System IP

\begin{tabular}{|c|c|c|c|}
\hline Name & Type & \multicolumn{2}{|c|}{ Dimensions or characteristics } \\
\hline \multirow{2}{*}{ Air Tank } & \multirow{2}{*}{ Round Pipe } & Volume (l) & 151 \\
\hline & & Initial pressure (bar) & 5 \\
\hline \multirow{2}{*}{$7565-2$} & \multirow{2}{*}{ Round Pipe } & Diameter (mm) & 25.4 \\
\hline & & Length (mm) & 1000 \\
\hline Air Tank Valve & $\begin{array}{l}\text { Valve that the lift is imposed } \\
\text { by an Actuator Part }\end{array}$ & Diameter (mm) & 25.4 \\
\hline \multirow{2}{*}{$7565-1$} & \multirow{2}{*}{ Round Pipe } & Diameter (mm) & 25.4 \\
\hline & & Length (mm) & 30 \\
\hline $\begin{array}{l}\text { Intake Port } \\
\text { Valve 1-6 }\end{array}$ & $\begin{array}{l}\text { Valve that the lift is imposed } \\
\text { by an Actuator Part }\end{array}$ & Diameter (mm) & 12.7 \\
\hline Yjun2 & $\begin{array}{l}\text { A spherical-shaped flow split } \\
\text { volume connected to one or } \\
\text { more flow components }\end{array}$ & Diameter (mm) & 45.7 \\
\hline \multirow{2}{*}{$\begin{array}{l}\text { 7016,7020,7021, } \\
7031,7037,7043\end{array}$} & \multirow{2}{*}{ Round Pipe } & Diameter (mm) & 32.4 \\
\hline & & Length (mm) & 60 \\
\hline $\begin{array}{l}\text { Throttle Valve } \\
1-6\end{array}$ & $\begin{array}{l}\text { Throttle that the throttle angle } \\
\text { is imposed by an Actuator Part }\end{array}$ & Diameter (mm) & 32.4 \\
\hline
\end{tabular}




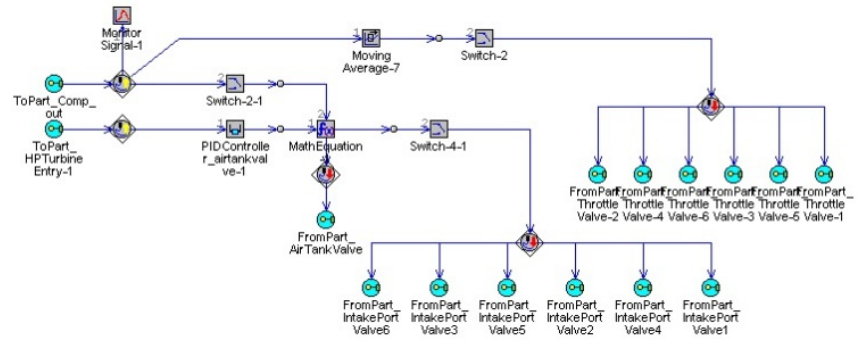

Figure 14. System diagram of IPSystem-Control-Unit

Figure 14 is the system diagram of the IPSystem-Control-Unit. Compared with System I, the deployment of the pressure sensors is changed:

- Compressor outlet pressure $\mathrm{p}_{2}$ (comes through ToPart_Comp_out)

- $\quad$ Exhaust manifold pressure $\mathrm{p}_{3}$ (comes through ToPart_HPTurbineEntry-1)

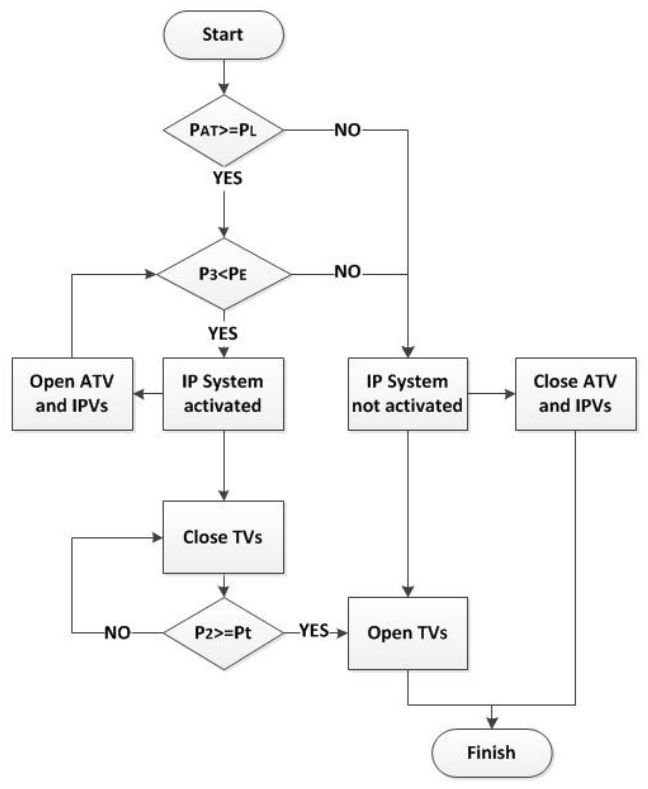

Figure 15. Flow chart of the System IP control strategy

Measurement of $\mathrm{p}_{3}$ is required because when System IP is working, the compressed air is injected into the small chamber composed by the IV, TV and intake valve in each intake port, the intake manifold pressure does not behave as in Systems I. Based on the pressure measurements, the valves are controlled to facilitate two operating modes. The flow chart of System IP control strategy is shown in Figure 15.

1. If the air tank pressure $\mathrm{p}_{\mathrm{AT}}$ is greater than the limit pressure $\mathrm{p}_{\mathrm{L}}$, which means the air tank pressure is sufficient to boost the engine, and at the same time, the compressor is unable to supply the target boost pressure, which means the turbine input pressure $\mathrm{p}_{3}$ is less than the target exhaust manifold pressure $\mathrm{p}_{\mathrm{E}}$, System IP will be activated. The control unit will open the ATV and the IPVs to inject compressed air into the cylinders, while the TVs in the intake ports will be closed prevent the compressed air leaking back into the inlet manifold. When the compressor outlet pressure $\mathrm{p}_{2}$ is greater than the TVs opening threshold pressure $\mathrm{p}_{\mathrm{t}}$, the TVs will fully open. System IP will be turned off when $\mathrm{p}_{3}$ is greater than $\mathrm{p}_{\mathrm{E}}$, and the ATV and IPVs will be closed.

2. If the air tank pressure is not sufficient to boost the engine, which means the air tank pressure $\mathrm{p}_{\mathrm{AT}}$ is less than the limit pressure $\mathrm{p}_{\mathrm{L}}$, whether the compressor can supply the target boost pressure or not, the control unit will not activate System IP. As a result, the ATV and IPVs will be closed and all six TVs will be opened to supply the air flow to the cylinders.

New modules, ESystem-Control-Unit (highlighted in green), and pneumatic hybrid system (highlighted in red) are added into the basic engine model to realise System $\mathrm{E}$ as shown in the Figure 16. The pneumatic hybrid system includes one air tank, one Air Tank Valve and pipework connected the air tank with the exhaust manifold.

\section{Simulation of the Engine with System $E$}

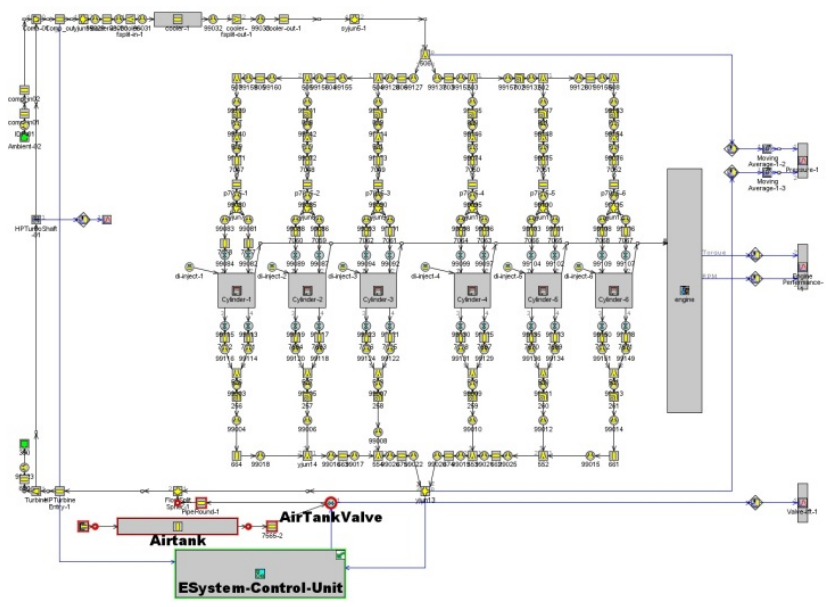

Figure 16. GT-POWER model of the engine with System E

The dimensions and characteristics for System E are shown in the Table 4. The size of the air tank, pipes and ATV are the same as used for the Systems I and IP to maintain consistency.

Figure 17 is the system diagram of the ESystem-Control-Unit. The function of the ESystem-Control-Unit is to control the ATV in System E. During a transient System E is activated. The ESystemControl-Unit uses two sensors to detect the pressures in the system:

- Compressor outlet pressure $\mathrm{p}_{2}$ (comes through ToPart_Comp_out)

- $\quad$ Exhaust manifold pressure $\mathrm{p}_{3}$ (comes through ToPart_yjun13)

Similarly to System IP, the exhaust manifold pressure had been chosen as the set point for control of the ATV opening. The ATV opening is controlled to facilitate two operating modes. The flow chart of System E control strategy is also shown in Figure 18. 
Table 4. Dimensions and characteristics for System E

\begin{tabular}{|c|c|c|c|}
\hline Name & Type & \multicolumn{2}{|c|}{ Dimensions or characteristics } \\
\hline \multirow{2}{*}{ Air Tank } & \multirow{2}{*}{ Round Pipe } & Volume (l) & 151 \\
\hline & & Initial pressure (bar) & 5 \\
\hline \multirow{2}{*}{$7565-2$} & \multirow{2}{*}{ Round Pipe } & Diameter (mm) & 25.4 \\
\hline & & Length (mm) & 1000 \\
\hline Air Tank Valve & $\begin{array}{l}\text { Valve that the lift is imposed } \\
\text { by an Actuator Part }\end{array}$ & Diameter (mm) & 25.4 \\
\hline \multirow{2}{*}{ PipeRound-1 } & \multirow{2}{*}{ Round Pipe } & Diameter (mm) & 25.4 \\
\hline & & Length (mm) & 30 \\
\hline FlowSplitSpher-1 & $\begin{array}{l}\text { A spherical-shaped flow split } \\
\text { volume connected to one or } \\
\text { more flow components }\end{array}$ & Diameter (mm) & 54 \\
\hline
\end{tabular}

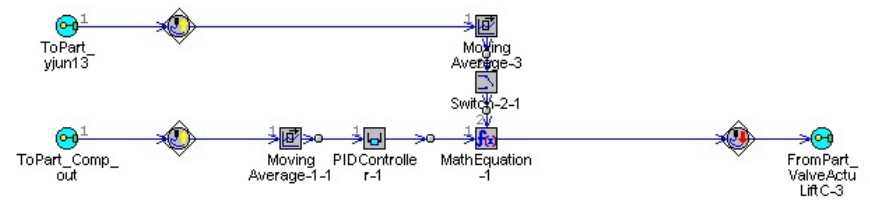

Figure 17 System diagram of ESystem-Control-Unit

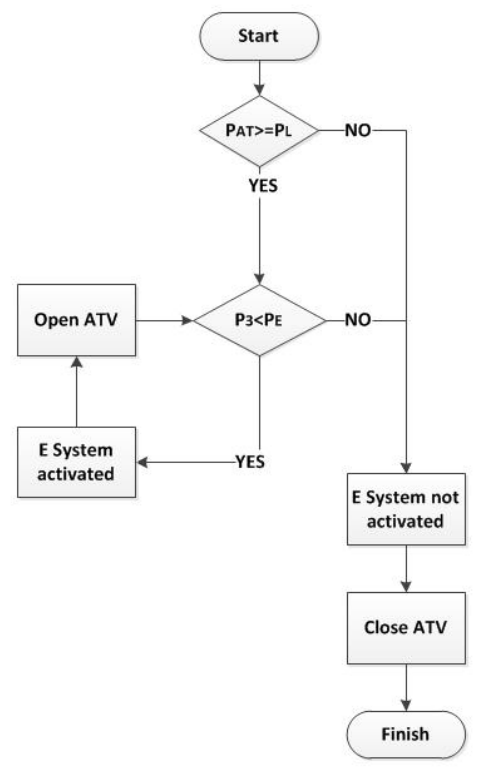

Figure 18. Flow chart of the System E control strategy

1. If the air tank pressure $\mathrm{p}_{\mathrm{AT}}$ is greater than the limit pressure $\mathrm{p}_{\mathrm{L}}$, the air tank pressure is sufficient to boost the engine. If at the same time, the compressor is unable to supply the target boost pressure (turbine input pressure $\mathrm{p}_{3}$ less than the target exhaust manifold pressure $\mathrm{P}_{\mathrm{E}}$ ) System E will be activated and the control unit will open the ATV to inject compressed air into the exhaust manifold to speed-up the turbocharger. When the exhaust manifold pressure $\mathrm{p}_{3}$ is equal or greater than the target exhaust manifold pressure $\mathrm{p}_{\mathrm{E}}$, the ATV will fully close.
2. If the air tank pressure is not sufficient to boost the engine, which means the air tank pressure $\mathrm{p}_{\mathrm{AT}}$ is less than the limit pressure $\mathrm{p}_{\mathrm{L}}$, the control unit will not activate the controller. As a result, the ATV will remain fully closed.

\section{Comparison of Simulation Results}

In this section, the maximum achievable performance from the three candidate pneumatic hybrid boost systems are compared for the situation when the engine accelerates from no load to full load at $1600 \mathrm{rpm}$. The obvious baseline for the result is the performance of the basic engine without any pneumatic hybrid boost system. The evaluation is done from each of two aspects.

1. Engine performance improvement;

2. Turbocharger operation condition;

\section{Engine Performance Improvement}

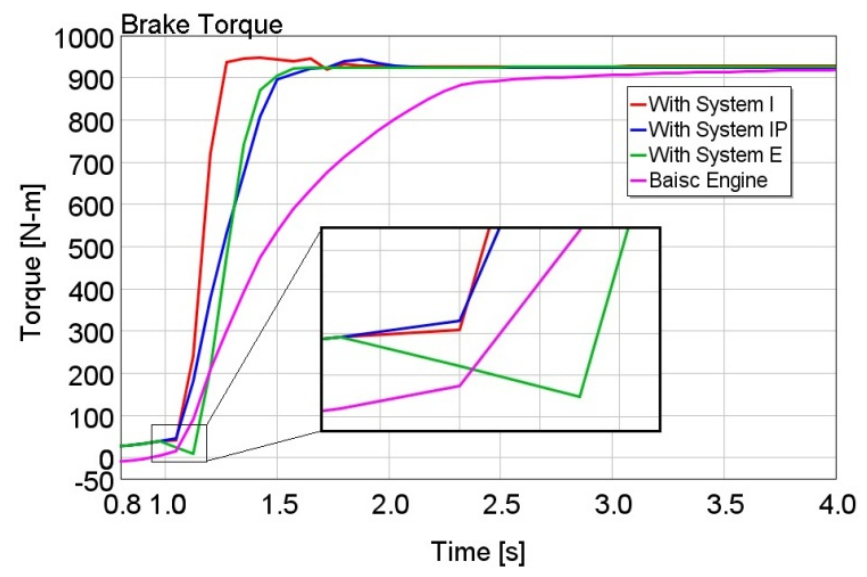

Figure 19. Brake torque response for each pneumatic hybrid boost system

Figure 19 shows the simulated full load acceleration response of the engine in the terms of engine brake torque. In the basic engine without any pneumatic hybrid boost system, torque can be seen to rise very slowly to reach the peak torque. The three pneumatic hybrid boost system all have a much sharper brake torque rise. Table 5 gives the time taken in each case to reach its peak torque output and their improvement to the basic engine performance expressed as the \% reduction in response time.

From Figure 19, it can be seen that Systems I and IP both have the fastest response in the very earliest stages of the acceleration while the engine with System E shows a decrease in brake torque output in this period. Such a decrease is likely to have an effect on driveability and represents a serious shortcoming. The reason is because in the engine with System $\mathrm{E}$ the whole manifold requires to be brought to its normal working pressure, slowing the response. These results also support the hypothesis that the location of air injection is fundamental to the result. It also can be seen in Figure 19 (inset) that compared with System I, the engine with System IP has the faster initial brake torque response because the compressed air is more quickly delivered to the cylinders in the first few cycles. Finally System I gives the shortest time to reach maximum brake torque. 
Table 5. Time to reach peak torque output of the four engine configurations and their improvement

\begin{tabular}{|l|l|l|}
\hline & Time to Reach Peak Torque Output - s & Improvement \\
\hline Basic Engine & 3 & - \\
\hline Engine with System I & 0.275 & $90.8 \%$ \\
\hline Engine withSystem IP & 0.65 & $78.3 \%$ \\
\hline Engine withSystem E & 0.575 & $80.8 \%$ \\
\hline
\end{tabular}

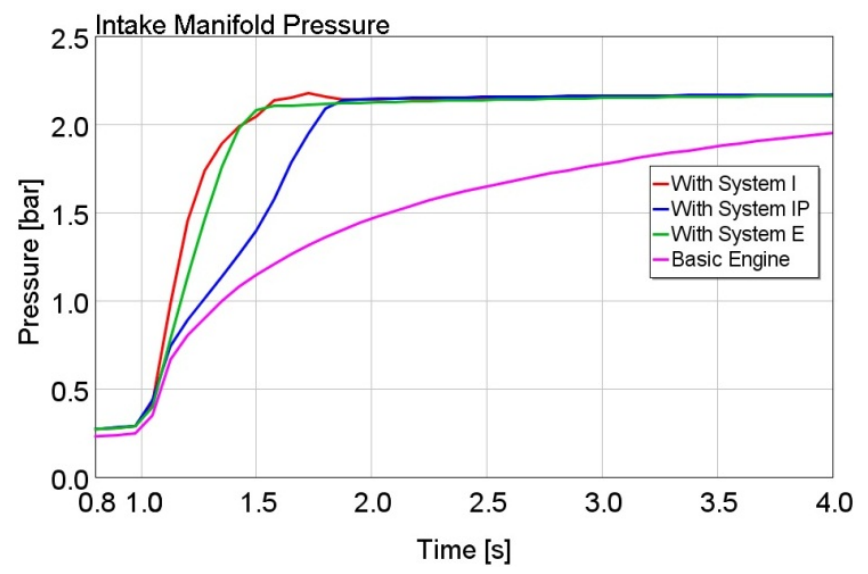

Figure 20. Intake manifold pressure for each pneumatic hybrid boost system

Figure 20 shows the intake manifold pressure change during the fullload acceleration at an engine speed 1600rpm for each of the four engine configurations. The engine with System I sees a rapid increase in intake manifold pressure. Once the engine with System E has reached normal turbocharger operating conditions it has the same ability to increase the intake manifold pressure. The reason that System IP is slower to build inlet manifold pressure is because as System IP simply needs less air from storage to achieve the changed state of the turbocharger. It remains that System IP still demonstrates a much faster intake manifold pressure build up compared with the basic engine.

\section{Turbocharger Operation Condition}

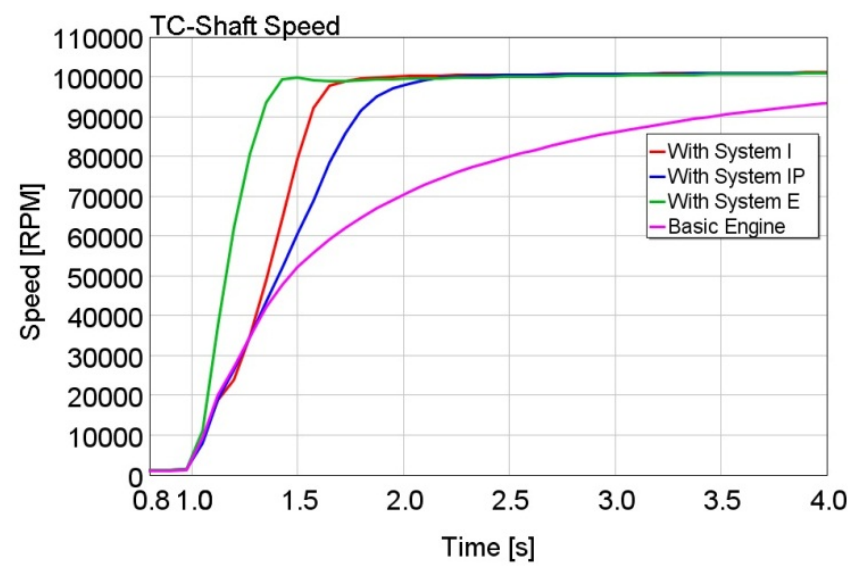

Figure 21. TC-Shaft speed for each pneumatic hybrid boost system Page 11 of 14
Figure 21 shows the turbocharger speed response during the simulation of a full-load acceleration at an engine speed 1600rpm for four engine configurations. The engine with System $\mathrm{E}$ shows the fastest acceleration of the turbocharger because of the direct path from the introduced high pressure air to the turbine rotor. The engine with Systems I and IP respectively both need to increase the turbocharger speed through the intermediary of high efficiency combustion in the cylinders. As a result, it can be seen in the Figure 21, from 1 to $1.3 \mathrm{~s}$, the engine with Systems I and IP demonstrate similar turbocharger shaft speed compared with the basic engine, and all slower than the engine with System E.

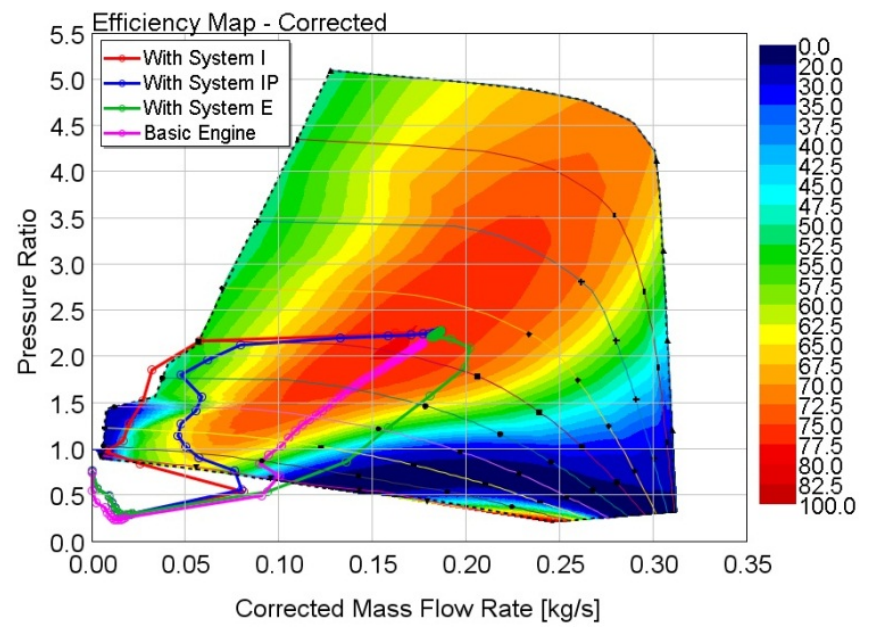

Figure 22. Turbocharger operation points on Compressor Efficiency map for each pneumatic hybrid boost system

Figure 22 shows operating points and loci on the compressor map. For each system type, it can be seen that the compressor of the engine with System I has already entered surge. This is because when System I is working, the compressed air is injected into the intake manifold while the IMV is closed. This behaviour substantially increases the risk that the compressor enters surge because the output of the compressor has been blocked by the IMV. To prevent the compressor entering surge, the injected air needs to be controlled by monitoring the compressor delivery pressure. Once the compressor operating point is near surge, the control unit will stop compressed air injection and open the IMV to move the compressor operating point away from the surge line.

Figure 22, demonstrates that with System IP there is less chance to cause the compressor to enter surge. This is because for System IP, only one intake port is blocked by the TV during compressed air injection. The compressor still can deliver the air into the cylinder through another intake port.

From Figure 22, System E can be recognized as the safest method to increase the turbocharger response compared with the Systems I and IP. The injection into the exhaust manifold accelerates the turbocharger shaft speed, as a result, the compressor's output pressure increases rapidly and well away from the surge line.

\section{Vehicle with Pneumatic Hybrid Boost System Simulation Result}

A 16 ton city bus equipped with diesel engine was modelled using the GT-Power code with parameters given in Table 6. The System I and 
IP respectively have been integrated into the basic bus model giving two different pneumatic hybrid vehicle configurations. The acceleration of the two types of vehicle has been simulated.

Table 6. Vehicle parameters

\begin{tabular}{|l|l|}
\hline Vehicle weight (kg) & 16500 \\
\hline Aerodynamic drag coefficient & 0.5 \\
\hline Frontal area (m2) & 5.69 \\
\hline Air density (kg/m3) & 1.225 \\
\hline Wheel radius (m) & 0.508 \\
\hline Rolling resistance coefficient & 0.013 \\
\hline Air tank volume (l) & 151 \\
\hline Starting tank pressure (bar) & 6 \\
\hline 1st gear ratio & 6.9 \\
\hline 2nd gear ratio & 4.13 \\
\hline 3rd gear ratio & 2.45 \\
\hline 4th gear ratio & 1.49 \\
\hline 5th gear ratio & 1 \\
\hline Final drive ratio & 5.125 \\
\hline
\end{tabular}

\section{Vehicle Simulation Results}

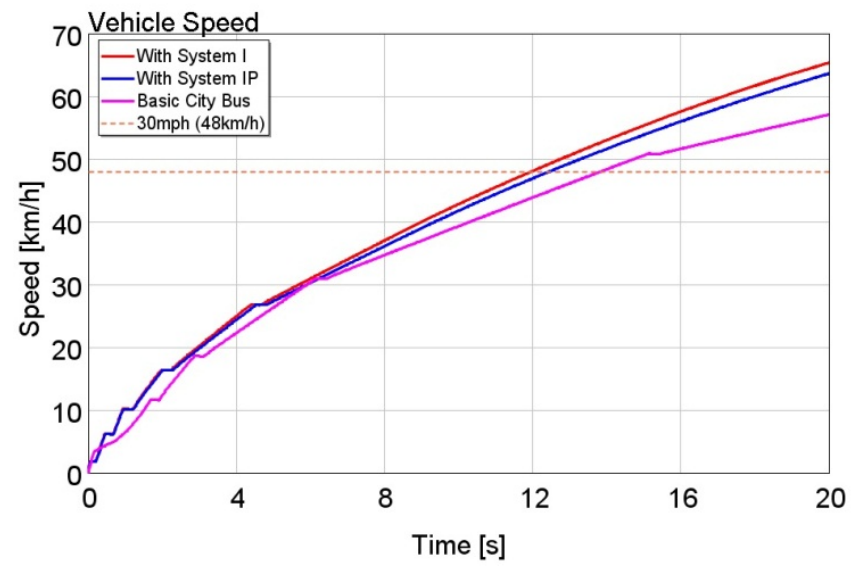

Figure 23. Vehicle speed during the acceleration

Figure 23 shows the vehicle speed change during the acceleration from 0 to 20 seconds. It can be seen, the vehicle with System I has the fastest acceleration performance. After $20 \mathrm{~s}$ acceleration, it reaches the speed of $65.3 \mathrm{~km} / \mathrm{h}$. The vehicle with System IP has the second fastest acceleration performance and reaches the speed of 63.5 $\mathrm{km} / \mathrm{h}$. The basic vehicle has the slowest acceleration performance which reaches the speed of $57 \mathrm{~km} / \mathrm{h}$ after $20 \mathrm{~s}$ acceleration. Table 7 shows the time for three vehicles to reach $48 \mathrm{~km} / \mathrm{h}$ (30 mile/h) which is the speed limit for the most urban city roads in the UK. The Systems I and IP reduce the acceleration times by $13 \%$ and $10 \%$ respectively.

Page 12 of 14
Table 7. Time to reach the speed of $48 \mathrm{~km} / \mathrm{h}$

\begin{tabular}{|l|l|l|}
\hline Pneumatic Hybrid Boost System & Time to Reach 48km/h - s & Improvement \\
\hline Basic Vehicle & 13.9 & - \\
\hline Vehicle with System I & 12.0 & $13.7 \%$ \\
\hline Vehicle with System IP & 12.7 & $8.6 \%$ \\
\hline
\end{tabular}

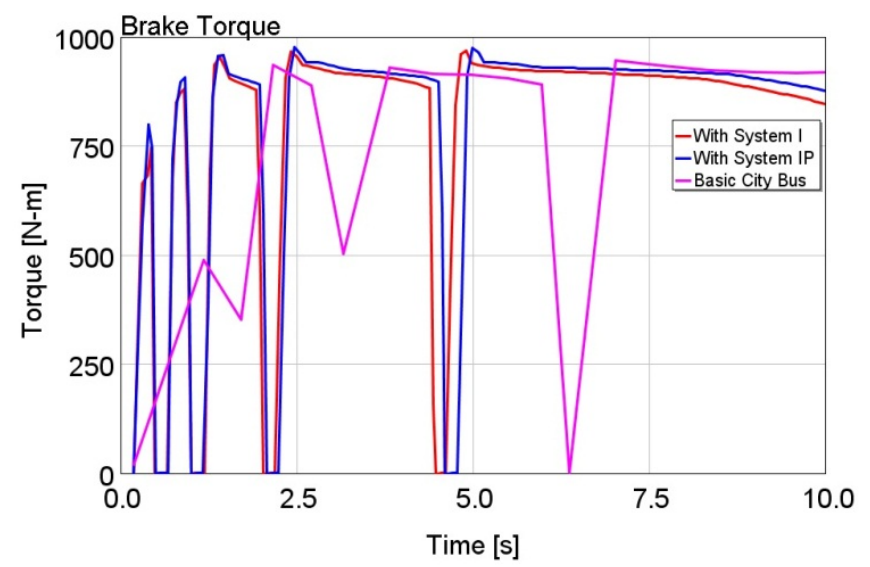

Figure 24. Engine brake torque response during the acceleration

Figure 24 shows the engine brake torque during acceleration. From the figure, it can be seen, at the beginning stage that the vehicle with the Systems I and IP respectively both have the greatest capability to build up the brake torque especially in lower gears.

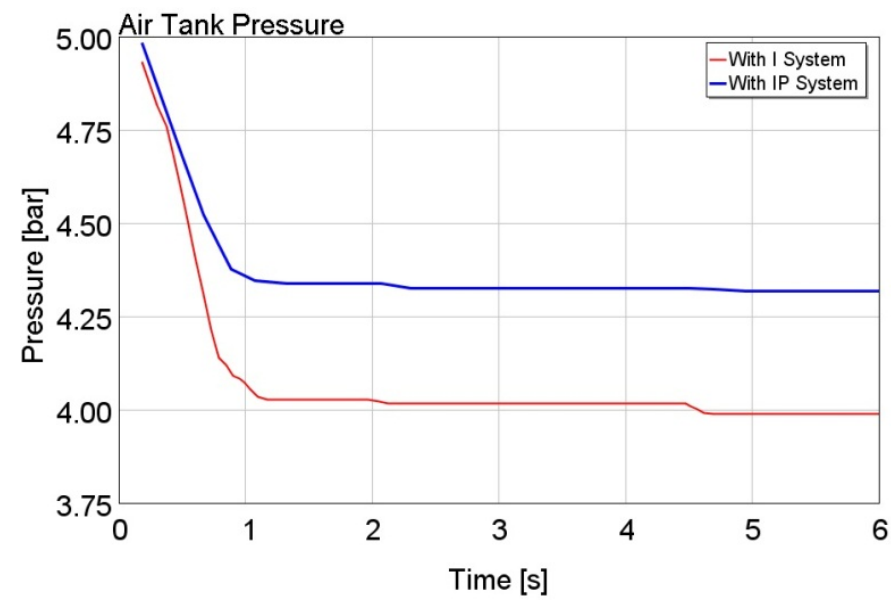

Figure 25 Air tank pressure drop during the acceleration

Figure 25 shows the air tank pressure drop during the acceleration. From the figure, it can be seen that System I use 1.02 bar air which is 0.32 bar more than the air usage of System IP which is 0.69 bar. The difference in air consumption is due to the efficiency of delivery in System IP. While air is delivered directly to the cylinders, the manifold is pressured by the slowly accelerating compressor in System I. It also can be learned from the figure that, the System I and IP activated when the vehicle start and after every gear change, and the lower gear, the more System I and System IP working time. 


\section{Conclusions}

Three kinds of pneumatic hybrid boost systems, respectively I, IP and E integrated into a six-cylinder 7.251 heavy-duty diesel engine for a city bus application have been modelled respectively in the 1-D engine simulation code GT-POWER. When the engine accelerates from no load to full load at $1600 \mathrm{rpm}$, the development of brake torque has been compared and analysed. The findings show:

- $\quad$ The engine with System I has the fastest engine response: 0.275 $\mathrm{s}$ to reach its maximum brake torque, compared with $3 \mathrm{~s}$ for the basic engine. The System I, IP and E all improve torque response time (to maximum torque) by $90.8 \%, 78.3 \%$ and $80.8 \%$ respectively. The engine with System $\mathrm{E}$ has a significantly lower brake torque output during the first few cycles which reduce the quality of the engine response.

- $\quad$ The simulation result indicates that System I carries the highest risk of compressor surge. To avoid surge, a control strategy can be implemented ensure the compressor operating point is kelp away from conditions where surge can develop. System IP carries a lower risk of surge because it does not block the output of the compressor. Because System E does not need a valve in the intake system there is no risk of surge.

The performance of the vehicle (city bus) has been also considered. A 16 ton city bus equipped with this engine has been modelled using GT-POWER. The Systems I and IP have been integrated respectively into the basic bus model. Both the Systems I and IP can be seen to significantly reduce the vehicle acceleration time through reduction of turbo-lag. For the speed range from 0 to $48 \mathrm{~km} / \mathrm{h}$ (30 mph) which is the speed limit for most urban roads in the UK, the vehicle with the Systems I and IP can reduce the acceleration time 13\% and 10\% respectively.

System IP offers considerable advantages over System I:

- $\quad$ Less use of air to achieve a similar brake torque response;

- Less likely to cause the compressor surge.

Therefore, System IP should be the appropriate candidate for the future research such as to develop a pneumatic hybrid system can achieve three functions: the regenerative braking when decelerating, boosting engine and eliminating the turbo-lag when accelerating, and the Stop-Start operation.

\section{Reference}

1. "GT-SUITE Overview," Retrieved from

https://www.gtisoft.com/products/GT-SUITE_Overview.php.

2. Bao, R., and Stobart, R., "Using Pneumatic Hybrid Technology to Reduce Fuel Consumption and Eliminate Turbo-Lag," SAE Techincal Paper 2013-01-1452, 2013, doi:10.4271/2013-011452.

3. Marx, M., Németh, H., and Gerum, E., "Improving the Torque Behaviour of Turbocharged Diesel Engines by Injecting Compressed Air," MTZ worldwide Edition 70(06):30-35, 2009.

4. Rakopoulos, C.D., and Giakoumis, E.G., "Diesel Engine Transient Operation: Principles of Operation and Simulation Analysis," Springer London, ISBN:9781848823747, 2009.

5. Cieslar, D., Collings, N., Dickinson, P., Glover, K. et al., "A Novel System for Reducing Turbo-Lag by Injection of Compressed Gas into the Exhaust Manifold," 2013, doi:10.4271/2013-01-1310.

Page 13 of 14
6. "Brief Introduction to YC6A Series Engine," Retrieved from http://www.yuchai.com/English/product/1208012224483371.ht m.

7. "Engine Performance Application Manual Version 7.4," GTSUITE, in online documentation.

8. Heywood, J.B., "Internal Combustion Engine Fundamentals," McGraw-Hill, New York, 1988.

9. "Air Starters SS175/SS350 Series," Retrieved from http://www.ingersollrandproducts.com/airstarters/pdfs/f237KB.pdf.

10. Lee, C., Zhao, H., and Ma, T., "Analysis of a Novel Mild Air Hybrid Engine Technology, Regenebd, for Buses and Commercial Vehicles," International Journal of Engine Research 13(3):274-286, 2012, doi:10.1177/1468087412437507.

\section{Contact Information}

Professor Richard Stobart

Department of Aeronautical and Automotive Engineering, Loughborough University,

Loughborough,

LE11 3TU, UK

r.k.stobart@lboro.ac.uk

\section{Acknowledgments}

This research is sponsored by the UK Engineering and Physical Science Research Council (EPSRC), grant reference number, EP/I00601X/I “A Cost-Effective Regenerative Air Hybrid Powertrain for Low Carbon Buses and Delivery Vehicles”. 


\section{Definitions/Abbreviations}

$\begin{array}{ll}\text { IM } & \text { improvement method } \\ \text { PBS } & \text { pneumatic boost system } \\ \text { BREES } & \begin{array}{l}\text { braking exhaust energy } \\ \text { storage }\end{array} \\ \text { EGR } & \text { exhaust gas recirculation } \\ \text { VGT } & \text { variable geometry turbine } \\ \text { EAT } & \text { electric assist technology } \\ \text { EM } & \text { electric motor } \\ \text { ISB } & \text { intake side boost } \\ \text { ATV } & \text { air tank valve } \\ \text { IMV } & \text { intake manifold valve } \\ \text { ESB } & \text { exhaust side boost } \\ \text { System I } & \text { intake boost system } \\ \text { System IP } & \text { intake port boost system } \\ \text { CV } & \text { exheck valve } \\ \text { TV } & \text { throttle valve } \\ \text { System E } & \end{array}$

